Fadini, A.A.B; Fermino, E.S.; Hoefel, J.L.M.; Suarez, C.F.S. Políticas públicas e participação social: perspectivas de turismo sustentável em Vargem (SP). Revista Brasileira de Ecoturismo, São Paulo, v.3, n.1, 2010, pp.91-108.

\title{
Políticas públicas e participação social: perspectivas de turismo sustentável em Vargem (SP)
}

\author{
Almerinda Antonia Barbosa Fadini, Evandro da Silva Fermino, \\ João Luiz de Moraes Hoefel, Cristiane Ferráz e Silva Suarez
}

\section{RESUMO}

O turismo desempenha um importante papel na proteção de Unidades de Conservação, tendo como um dos grandes desafios a implementação de uma gestão baseada na participação social, na ética e na sustentabilidade dos seus recursos naturais. Neste sentido, o município de Vargem-SP que está inserido na Área de Proteção Ambiental do Sistema Cantareira, busca consolidar a atividade turística como uma fonte de renda mais sustentável e complementar para o município. Este artigo, que é parte integrante de uma pesquisa financiada pela FAPESP - Fundação de Amparo à Pesquisa do Estado de São Paulo, trata das articulações que vem ocorrendo em Vargem, voltadas para estimular uma maior participação dos diversos atores sociais nas políticas públicas locais, em especial, as relacionados ao turismo. A metodologia foi baseada na coleta de dados com os diferentes atores e em pesquisas de campo de forma a identificar as características do município e da comunidade local. Os resultados obtidos até o presente momento denotam que existem diversos atrativos naturais e culturais na localidade, porém, a população não os percebe como potenciais para incrementar as atividades turísticas e outra constatação é a incipiente participação desta nos processos decisórios de Vargem-SP.

PALAVRAS-CHAVE: Turismo Sustentável, Participação Social, Políticas Públicas.

\section{Public Policies and Social Participation: Perspectives on Sustainable Tourism in Vargem - SP, Brazil}

\section{ABSTRACT}

Tourism plays a key role in the protection of conservation areas, having as one of the greatest challenges the implementation of a management plan based on social participation, ethics and sustainability of the natural resources. In this sense, the municipality of Vargem - SP, Brazil, which is part of the Cantareira System Environmental Protected Area, seeks to consolidate tourism activity as a sustainable and complementary source of local income. This article, which is part of a research funded by FAPESP (São Paulo State Research Fund), studies the articulations in Vargem -SP that stimulate a greater participation of the diverse social actors in local public policies, in particular those related to tourism. The methodology was based on data collection with several social actors and with field surveys in order to identify the characteristics of the region and the local population. The results obtained so far denote that there are several natural and cultural attractions in the locality, however, the population does not perceive them as potential to increase tourism activities and another finding is the incipient participation of the local people in decision-making process of Vargem - SP.

KEYWORDS: Sustainable Tourism, Social Participation, Public Policies. 
Políticas Públicas e Participação Social: Perspectivas de Turismo: Sustentável em Vargem (SP)

\section{Os movimentos ambientalistas e o processo de participação}

A participação social nos movimentos ambientalistas vem se intensificando nos últimos anos no Brasil e no mundo em decorrência de diversos fatores como o agravamento da crise ambiental, o acesso aos meios de comunicação e a sensibilização e a necessidade de se posicionar frente a problemática socioambiental e buscar de forma coletiva soluções.

Estes movimentos se acentuaram especialmente a partir da década de 1960, possibilitando extraordinárias repercussões e mudanças de conceitos e de atitudes, sendo que dentre as articulações e ações destacam-se as relacionadas aos encontros e conferências mundiais voltados para a sustentabilidade ambiental. No entanto, é importante destacar que estes eventos retrataram, respeitando as suas especificidades, os diferentes interesses econômicos relacionados com esta questão.

$\mathrm{Na}$ Conferência Mundial sobre o Meio Ambiente Humano de Estocolmo em 1972, durante a sua preparação, apareceram duas posições apostas, uma denominada dos catastróficos que segundo Sachs (2000), era considerada como pessimista e anunciava o apocalipse para o dia seguinte, caso o crescimento demográfico e econômico - ou pelo menos o crescimento do consumo - não fossem estagnados (defensores do crescimento zero); idéias estas derivadas do estudo desenvolvido pelo Clube de Roma, denominado Limites do Crescimento, e as assumidas entre os que previam abundância dos recursos naturais (chamados também de defensores do desenvolvimento a qualquer custo), acreditando que as preocupações eram descabidas e que atrasariam e inibiriam os esforços dos países em desenvolvimento rumo à industrialização (SACHS, 2000; BRUSEKE, 1998).

Para Furtado (1974), no que diz respeito ao Clube de Roma, não era o caso de concordar com todos os aspectos metodológicos e conclusões desse estudo, e sim destacar o mérito das primeiras discussões em torno da destruição dos recursos naturais, em especial os não-renováveis, durante todo o processo de civilização por determinados países, questões que, segundo o autor, os economistas do desenvolvimento econômico sempre trataram de deixar à sombra.

Furtado destaca ainda que os dados desse relatório confirmavam a grande dependência e consumo dos países altamente industrializados por recursos naturais dos demais países, os quais em sua maioria eram subdesenvolvidos. Deste modo, para o autor, a visão de vários economistas que defendiam que o progresso dos países do terceiro mundo ocorreria mediante a reprodução dos sistemas adotados pelos países que lideraram a sociedade industrial, ou seja, através do acúmulo do capital e dos investimentos nos meios tecnológicos, reforçavam "o mito de um desenvolvimento econômico", o qual, segundo o autor, não considerava as consequências da tese do crescimento, que se expressavam em diversos e significativos impactos socioambientais e culturais.

O relatório Limites do Crescimento alertava que se o conceito de desenvolvi- 
mento econômico chegasse a concretizar-se, isto é, se as formas de vida dos povos ricos universalizassem, a pressão sobre os recursos não- renováveis e a poluição do meio ambiente seriam de tal ordem que o sistema econômico mundial entraria em um colapso (FURTADO, 1974; BRUSEKE, 1998).

A partir destas discussões, durante a Conferência em Estocolmo, estas posições extremistas foram descartadas e iniciou-se a formulação de novos paradigmas, como a ideia de um outro desenvolvimento, fundado no conceito de desenvolvimento sustentável. Este debate envolveu os representantes de mais de 100 países e de 250 organizações não governamentais que a partir de diferentes interesses participaram e defenderam posições em nome de cidadãos numa esfera global.

Embora o novo conceito tenha sido debatido em Estocolmo, apenas em 1987 é que foi apresentado o documento Nosso Futuro Comum, considerado como um dos mais importantes sobre a questão ambiental, formulado pela Comissão Mundial para o Meio Ambiente e Desenvolvimento - CMMA, no qual se define o termo desenvolvimento sustentável, como: "aquele que responde às necessidades do presente de forma igualitária, mas sem comprometer as possibilidades de sobrevivência e prosperidade das gerações futuras", estabelecendo que a pobreza, a desigualdade e a degradação ambiental não podem ser analisadas de maneira isolada (COMISSÃO MUNDIAL SOBRE MEIO AMBIENTE E DESENVOLVIMENTO - CMMAD, 1991).

No documento Nosso Futuro Comum (CMMAD, 1991), propõe-se também rever valores, comportamentos e pensamentos, como se verifica a seguir:

Para conseguir resolver problemas globais, temos de criar novas maneiras de pensar, desenvolver novos critérios morais e de valores, e sem dúvida novos padrões de comportamento. A humanidade se encontra às portas de um novo estágio em seu desenvolvimento. Deveríamos não só promover a expansão de sua base material, científica e técnica, mas também, o que é mais importante, incutir novos valores e aspirações humanistas na psicologia humana, pois a sabedoria e o humanismo são "verdades eternas" que constituem a base da humanidade (CMMAD, 1991, p. 39).

No entanto para Morin (2002), é necessária uma noção mais rica e complexa do desenvolvimento, já que até mesmo o dito sustentável, segue o modo técnicoeconômico. Desta forma, para o autor, o desenvolvimento não deve ser compreendido somente como material, mas também intelectual, afetivo, moral, entre outros. Seguindo nesta linha, Sachs (2000) destaca que para alcançar de forma solidária a sustentabilidade, tanto para a geração atual quanto para as próximas, devem ser considerados os seguintes critérios: o respeito e responsabilidade a existência e diversidade da natureza e aos princípios de igualdade, de educação e justiça, da diversidade das culturas, dos valores humanos e enfoca o papel da gestão participativa. 
Quando ocorreu a Conferência das Nações Unidas sobre o Meio Ambiente e Desenvolvimento, no Rio de Janeiro em 1992, as discussões se fundamentavam na elaboração de estratégias e medidas com a finalidade de deter e reverter a degradação ambiental, bem como promover o desenvolvimento sustentável do meio ambiente (FOLADORI, 2001). No entanto, embora os países em desenvolvimento tenham aprofundado as análises da responsabilidade dos países desenvolvidos que apresentam desde a primeira Revolução Industrial; padrões elevados de vida, consumo exacerbado, desperdício e poluição; estes países ricos, em especial os Estados Unidos, tentaram conduzir as discussões no plano global e sem fixar pontos específicos, deste modo, não assumiriam responsabilidades quanto à questão da produção e do próprio funcionamento do capitalismo (NOVAES, 2002; FOLADORI, 2001).

Embora os resultados deste encontro tenham gerado muitas críticas desfavoráveis, a maioria dos participantes creditou como avanços a criação das Convenções sobre Mudanças Climáticas e sobre a Conservação da Diversidade Biológica e a Agenda 21. Esta Agenda consiste em um plano que define as estratégias e ações para chegar ao desenvolvimento sustentável para este século, através de medidas governamentais e não-governamentais, e que de forma participativa sejam adotadas nas escalas mundiais, regionais e locais, atingindo toda a esfera planetária.

Esta conferência teve uma imensa repercussão envolvendo mais de uma centena de representantes de países, de chefes de Estado, ONGs, jornalistas e de milhares de participantes, propiciando um forte debate e mobilização da comunidade internacional em torno da necessidade de mudança de comportamento para garantir a preservação da vida no planeta.

Em 2002 ocorreu a Conferência Rio+10 em Johanesburgo, na África do Sul, a qual contou com um público parecido com o das conferências anteriores. Neste evento, os países concordaram que é necessário cumprir as convenções de reduzir as emissões de poluentes e conservar a diversidade biológica, que é preciso aumentar a ajuda dos países mais ricos aos mais pobres, como se estabeleceu na Agenda 21, porém pouco se avançou. Foi adotado o Compromisso de Johanesburgo para o Desenvolvimento Sustentável, o qual, como declaração, foi considerado muito prolixo, mas, quanto aos compromissos, ficou a desejar por estar distante de uma verdadeira agenda para ação. Outra crítica refere-se ao fato dos compromissos serem considerados vagos e sem prazos para serem alcançados (SELA apud DIAS, 2003).

Outra ressalva é que, embora as discussões que inicialmente eram voltadas para levar os compromissos à prática, fragilizaram-se devido ao atentado ao World Trade Center nos Estados Unidos em 2001, o qual acabou por ocupar o panorama ambiental com questões voltadas aos ataques terroristas e como contê-los, além da ausência de importantes lideranças políticas internacionais e de um maior espaço na mídia para a importância de tal evento

Fadini (2005) destaca que embora outros interesses não essencialmente ambientais apresentem-se constantemente nas conferências mundiais, as discussões sobre o agravamento dos problemas de poluição, contaminações, uso dos recursos não- 
renováveis, juntamente com a maior atenção e divulgação destes conteúdos, por parte dos veículos de comunicação, vêm acentuando e aprofundando a discussão da questão ambiental em todas as esferas da sociedade, extrapolando as decisões estritamente técnicas e governamentais. Estes avanços se apresentam na implantação de instrumentos de mudanças de atitudes e de valores e que vem transformando-se em políticas públicas, como os projetos de Educação Ambiental, a gestão integrada e planejamentos participativos que apontam para decisões conjuntas, como planos diretores, estatutos das cidades, projetos de cidades sustentáveis e a implantação de Agendas 21 regionais e locais, os quais vêm se fortalecendo e consolidando como importantes agentes de ação sustentável.

Neste sentido, a formulação de políticas públicas vem possibilitando a participação social, que segundo Loureiro (2003) entende-se como um processo social que gera a interação entre diferentes atores sociais. Embora nos últimos anos pode-se verificar um interesse público para a descentralização do Estado, possibilitando a gestão participativa, um dos grandes desafios ainda, para Irving (2006), é o "fazer coletivo" e o entendimento da participação social como garantia ética de sustentabilidade em projetos de conservação de recursos renováveis e/ou desenvolvimento.

O segmento do turismo desempenha, dentro deste contexto, um importante papel na construção de uma gestão participativa e sustentável dos lugares, já que o mesmo abrange uma ampla gama de serviços e apresenta um papel importante no conjunto das atividades produtivas. Nesse contexto, para Cruz (2000) a atividade turística ganha destaque entre as políticas públicas setoriais no país, tornando-se uma das prioridades nacionais.

\section{Turismo, Meio Ambiente e Participação Social}

O turismo é reconhecido como uma atividade importante dentro da área de lazer que, como tal, pode contribuir para a melhoria da qualidade de vida da população, desde que a mesma tenha conseguido satisfazer suas necessidades mínimas de subsistência e atingido boas condições de saúde, moradia e educação.

Neste contexto, o planejamento e a gestão do turismo vêm apresentando-se como uma grande preocupação para todos os profissionais interessados na sustentabilidade da atividade. Tal preocupação se fundamenta nos inúmeros exemplos de impactos socioambientais, econômicos e culturais negativos existentes em todo o mundo, decorrentes do crescimento desordenado da atividade turística.

Assim, sem negar a relevância econômica da atividade e seu potencial como difusora de culturas, é importante promover pesquisas sobre os reflexos efetivos da atividade turística na sociedade, tornando-se necessário propostas de turismo sustentável, o qual é caracterizado como uma alternativa ao turismo de massa, que, durante anos vem agredindo as paisagens e destruindo os ecossistemas (SUAREZ, 2005). 
Entre os sérios problemas decorrentes do segmento turístico encontra-se a ausência de planejamentos que consideram a participação como prioridade para as tomadas de decisão da localidade, originando novos problemas decorrentes das transformações do uso do solo e da descaracterização sociocultural e ambiental dos lugares.

Neste contexto, Maricato (2000) desenvolve uma crítica aos planos que consideram a força do mercado, num processo de criação e de reprodução de excluídos, enfatizando a importância de planejamentos participativos:

[...]sem a participação social a implementação do plano se torna inviável e, ele mesmo, inaceitável ao tomar os moradores como objeto e não como sujeitos. O processo de formulação participativa de um plano pode ser mais importante que o plano em si, dependendo da verificação de certas condições. Isto porque ele pode criar uma esfera ampla de debate e legitimar os participantes com seus pontos de vista diferentes e conflitantes. A constituição e consolidação dessa esfera de participação política é que poderá auxiliar na implementação de um sistema de planejamento e nas reorientações ao plano (MARICATO, 2000, p. 180).

Maricato (2000), deste modo, enfatiza que na maioria das vezes há a ausência de uma sintonia entre idéias (diretrizes, metas, propostas) com a realidade do lugar, e como muitas vezes o lugar está fora das idéias, tornando- ilegítimo, como demonstra na citação de Francisco de Oliveira para Maricato (2000): As idéias fora do lugar e o lugar fora das idéias.

Deste modo, a necessidade de uma maior participação nos processos decisórios ocorrerá segundo Dowbor (1999), a partir de um engajamento que busque uma melhor qualidade de vida a todos, e que esse esforço conjunto resulte em um poder local:

O poder local, com os seus instrumentos básicos, que são a participação comunitária e o planejamento descentralizado, constitui, nesse sentido, um mecanismo de ordenamento político e econômico que já deu provas de eficiência, em particular nos países desenvolvidos. Ele é sem dúvida o grande recurso subutilizado no país (DOWBOR, 1999, p. 83).

Moreira (1980) em seu livro intitulado $A$ força do povo, discute sobre a importância de planos conjuntos que envolvam o cidadão comum nos processos de decisões, demonstrando aos mesmos a necessidade de atitudes comunitárias e democráticas para a obtenção de conquistas mais efetivas, consistentes e por que não dizer, prazerosas. 
Estas colocações demonstram que para a obtenção de um turismo sustentável este deve perpassar por planejamentos que busquem agregar idéias e posicionamentos conjuntos visando contribuir para a melhoria da qualidade de vida e ambiental dos lugares onde estiver inserido. Neste sentido, destaca-se a sua presença nas Unidades de Conservação (UC's), as quais, no Brasil, foram criadas com o objetivo de minimizar os impactos ambientais causados pela ocupação desordenada em áreas com características naturais e culturais singulares, bem como difundir na sociedade a importância da preservação e conservação (SÃO PAULO, 2000).

Dentre as diversas UC's, encontram-se as Áreas de Proteção Ambiental APA's, as quais devido as suas características socioambientais e culturais necessitam de um planejamento que considere a manutenção da integridade da biodiversidade e da qualidade de vida das populações humanas presentes nesta unidade, tornando um grande desafio o cumprimento dos objetivos propostos para esta Unidade de Conservação.

Por este motivo, é necessário exercer um conjunto de ações políticas, legislativas e administrativas de forma democrática, visando uma gestão que contemple a participação equitativa dos diversos atores sociais, os quais possam manifestar e defender as suas necessidades, anseios, oportunidades e interesses no planejamento sustentável das APA's.

Um planejamento que considera a comunidade local em todas as fases, desde a sua elaboração, implantação, monitoramento até a avaliação, pode ser denominado de participativo. Porém como já mencionado este processo nem sempre é contemplado, devido à ainda incipiente experiência em planos que consideram a participação funcional, interativa e/ou a automobilização.

Sobre a participação no manejo de áreas protegidas, Pimbert e Pretty (2000), definem a participação funcional como uma prática utilizada quando a comunidade ainda não está organizada, dependendo muitas vezes de agentes externos para o estabelecimento dos objetivos e condução das discussões. Este processo pode tornarse mais ágil e rápido, porém deve-se atentar para a possibilidade de dependência externa no processo de decisão, por este motivo deve-se estimular a comunidade para uma transição desta atuação para uma participação mais interativa. Para estes autores, a participação interativa enriquece a todos os envolvidos, desde os planejadores técnicos como a própria comunidade, já que envolve uma conjunção de conhecimentos e uma autodeterminação na solução de problemas locais através de um contínuo processo de aprendizagem. Já com relação à automobilização, esta depende de uma sociedade organizada e muitas vezes, altamente politizada, já que envolve a iniciativa conjunta de discutir os sistemas político-econômicos, sócio-culturais e ambientais estabelecidos e propor a transformação a partir de ações coletivas.

Todas estas formas de participação apresentadas por Pimbert e Pretty (2000) denotam a importância de uma gestão participativa e democrática não somente para Unidades de Conservação, mas também, para qualquer outra unidade de planeja- 
mento. Para Diegues e Nogara (1999), uma gestão deve considerar não somente as necessidades de conservação dos ecossistemas, mas também as aspirações locais, os modos de vida e, sobretudo a contribuição histórica das populações tradicionais para a conservação ambiental.

Uma maior participação dos atores sociais em um planejamento é fundamental para a solução de conflitos existentes, principalmente no interior de uma APA, já que os direitos de propriedade são preservados, o que para Cabral \& Souza (2002), pode afetar interesses políticos/econômicos particulares e também o modo de vida da população. Outra preocupação é o fato de que muitas Unidades de Conservação ainda não foram regularizadas, comprometendo a gestão e o planejamento, no que concerne à implantação do plano de manejo, do diagnóstico e zoneamento ambiental e a criação do conselho gestor, como é o caso da APA do Sistema Cantareira, a qual foi criada em 1998 e somente em 2009 é que houve a composição do Conselho Gestor.

Por este motivo a gestão participativa torna-se um instrumento valioso para minimizar conflitos e também para de forma conjunta exigir a agilização dos processos burocráticos para a definitiva instalação de uma APA. Neste contexto, deve-se também identificar quais são os principais usos e seus impactos, para buscar formas adequadas de minimizá-los e até mesmo apresentar novas alternativas econômicas sustentáveis para estas áreas protegidas, assim, a adoção do planejamento turístico é extremamente importante para incentivar processos participativos.

Uma das formas para alcançar a participação de todos os segmentos sociais, inclusive do turista, é através da incorporação da Educação Ambiental em projetos de sensibilização, de orientação e de propostas de solução que visem à promoção do uso sustentável dos recursos naturais e a garantia da melhoria da qualidade de vida a todos (FADINI, 2005).

A Educação Ambiental pode promover a reflexão sobre o papel do cidadão na conservação dos recursos naturais e dos aspectos sócio-culturais, através da valorização dos lugares e de mudanças de comportamento, auxiliando numa gestão participativa, em que todos os atores sociais possam buscar conjuntamente a construção de alternativas sustentáveis para as localidades turísticas em especial em Áreas de Proteção Ambiental, contribuindo para, como aponta FREIRE (1975), uma práxis transformadora através da ação e reflexão.

\section{Processos Históricos de Emancipação Municipal}

Desde meados de 1960 vem-se incrementando a participação social nos espaços públicos, como fóruns coletivos, audiências públicas e abaixo-assinados, contribuindo assim para uma mudança radical das políticas públicas. Mesmo que anteriormente esta participação estivesse mais voltada ao caráter reivindicatório, principalmente pautada em embates com o Estado, não se deve descartar a importância destes movimentos como um processo de amadurecimento social. 
Santos (2005) destaca as experiências da gestão municipal com o envolvimento popular, nos municípios de Lajes/SC e Boa Esperança/ES, no início da década de 1970, onde:

O poder público local procurou valorizar o envolvimento e a participação das pessoas na construção de alternativas para a superação da situação de estagnação econômica, pobreza e dependência diante dos governos estadual e federal (SANTOS, 2005, p.85).

Estas experiências, entre outras, vêm contribuindo para que a participação social se consolide, sendo que um dos exemplos ocorreu em 1986 quando a Assembleia Nacional Constituinte, durante a elaboração da nova constituição, procurou incorporar este tema, inclusive criando planos de ação buscando a legalização desta participação social. Neste sentido, é que neste artigo são apresentadas as transformações socioambientais e os processos participativos em Vargem-SP. Este município encontra-se localizado na Região Bragantina e integra a Área de Proteção Ambiental - APA do Sistema Cantareira. Esta Unidade de Conservação foi instituída pela Lei Estadual $\mathrm{n}^{\circ}$. 10.111/1998 e abrange os municípios de Mairiporã, Atibaia, Nazaré Paulista, Piracaia, Joanópolis, Vargem e Bragança Paulista (SÃO PAULO, 2000).

Este município, historicamente, vem passando por transformações geradas por diversos fatores - políticos, sociais, econômicos, culturais e ambientais - afetando diretamente a população local, a qual tem devido a estas circunstâncias se posicionado, como é o caso do processo de emancipação política do município.

Para Molinari (2004), a população residente no Distrito de Vargem decidiu em 1963 buscar a emancipação do município de Bragança Paulista, sendo que neste período foi realizado um plebiscito, que segundo as palavras do autor,"por incrivel que pareça resultou em empate".

Devido a este empate, a decisão teve de ser tomada pela Assembleia Legislativa Estadual, que conforme a Lei Estadual $\mathrm{n}^{\circ}$ 8059, de 28 de fevereiro de 1964, foi elevado à categoria de município. No entanto, em 1964, foi expedido um mandado de segurança pelo então prefeito de Bragança Paulista-SP, que não se conformou com a decisão de Vargem ter se tornado um município, utilizando como argumento as perdas econômicas, territoriais e eleitorais de Bragança Paulista pressionando Vargem a retornar em 1969 a condição de Distrito de Bragança Paulista.

Segundo Molinari (2004), as lideranças locais quando souberam desta decisão organizaram um dos primeiros grandes movimentos sociais, em uma tentativa de derrubar este mandado de segurança, indo até mesmo alguns representantes ao Supremo Tribunal Federal, porém esta tentativa não surtiu resultados positivos.

Após a assinatura pelo governador de São Paulo, aos 31 de julho de 1990, da Lei Complementar $n^{\circ} 651$, que dispunha sobre: a criação, fusão, incorporação, e desmembramentos de município, outro grupo composto por diferentes atores sociais elaboraram o Estatuto Social de Comissão de Emancipação do Distrito de Vargem, de 13 
de maio de 1991. Após o cadastramento nos órgãos competentes descritos na Lei, esta comissão iniciou o movimento pela emancipação com os moradores da localidade, enquanto Bragança Paulista lutava para a continuidade da área como distrito.

Em 1991, ocorreu a segunda tentativa de emancipação e participaram deste novo plebiscito 2.111 de um total de 2.718 eleitores, sendo aprovada a emancipação por um total de 1.761 votos e em 1992, houve a eleição para prefeito e para nove vereadores (MOLINARI, 2004). Uma curiosidade apresentada pelo autor é que entre a data da realização do plebiscito e a da primeira eleição passaram-se 17 meses e neste período houve um aumento significativo de eleitores, passando de 2.718 para 3.614 .

Assim no primeiro dia do ano de 1993 , foi realizado o primeiro grande evento do novo município, contanto com um grande numero de participantes, e segundo Molinari (2004) esta foi uma conquista que contou com uma ativa participação popular.

\section{Turismo e Participação em Vargem}

A APA do Sistema Cantareira, na qual o município de Vargem - SP está inserido, é uma Unidade de Conservação de Uso Sustentável e seus objetivos na região relacionam-se com a manutenção e melhoria da qualidade da água especialmente dos municípios no entorno dos reservatórios do Sistema Cantareira, que abastecem a Região Metropolitana de São Paulo e regulam o fluxo de água para a Região Metropolitana de Campinas.

Nas últimas décadas, em função do acesso facilitado a esta região, através das Rodovias D. Pedro I e Fernão Dias, esta APA, a qual está em processo de regulamentação, vem se tornando alvo de empreendimentos imobiliários os mais diversos, consolidando um processo crescente de ocupação do solo e uso turístico desordenado. Esta realidade tem exigido a elaboração e implantação de estudos, projetos e planos de ação que identifiquem as principais transformações regionais e que possibilitem uma gestão sustentável de seus recursos naturais.

Uma análise do município de Vargem-SP indica que existem entre os diferentes grupos sociais, abordagens e percepções diferenciadas sobre a problemática ambiental que vêm refletindo-se nas propostas de desenvolvimento regional e gerando determinados conflitos. Entre estes grupos é possível destacar representantes do poder público, técnicos de órgãos públicos e privados, moradores da região, turistas de fim de semana, de segunda residência e excursionistas, empresários e membros de entidades ambientalistas.

Os conflitos existentes podem ser claramente evidenciados nas atuais propostas de uso para o Sistema Cantareira, em especial no entorno dos reservatórios. Apesar das restrições impostas pela legislação ambiental vigente e por compor a Unidade de Conservação, usos econômicos diversos, muitas vezes inadequados para a área, vêm sendo sugeridos e implantados gerando impactos socioambientais e culturais, 
que precisam ser adequadamente analisados.

Com relação às principais atividades econômicas do município, destacam-se as do ramo imobiliário associadas ao parcelamento do solo, as práticas agropecuárias, as olarias, atividades de mineração e as do segmento turístico. Dos usos identificados, os mais dinâmicos, impactantes e transformadores são os associados aos processos turísticos e de urbanização que vêm reconfigurando a paisagem e afetando as condições ambientais da área de estudo.

Esta expansão urbana estimulada pelo crescimento da Região Metropolitana de São Paulo, rumo à Região Bragantina, e por políticas municipais de incremento urbano, vem ocorrendo de forma intensa e caracteriza-se pela proliferação de loteamentos de alta densidade populacional, implantados sem uma adequada infraestrutura básica. $O$ crescimento turístico vem ocorrendo em especial no entorno do Reservatório dos Rios Jaguary/Jacareí, e é caracterizado pela presença de marinas, pousadas, condomínios de segunda residência e chácaras de final de semana, como se pode verificar na Figura 1.
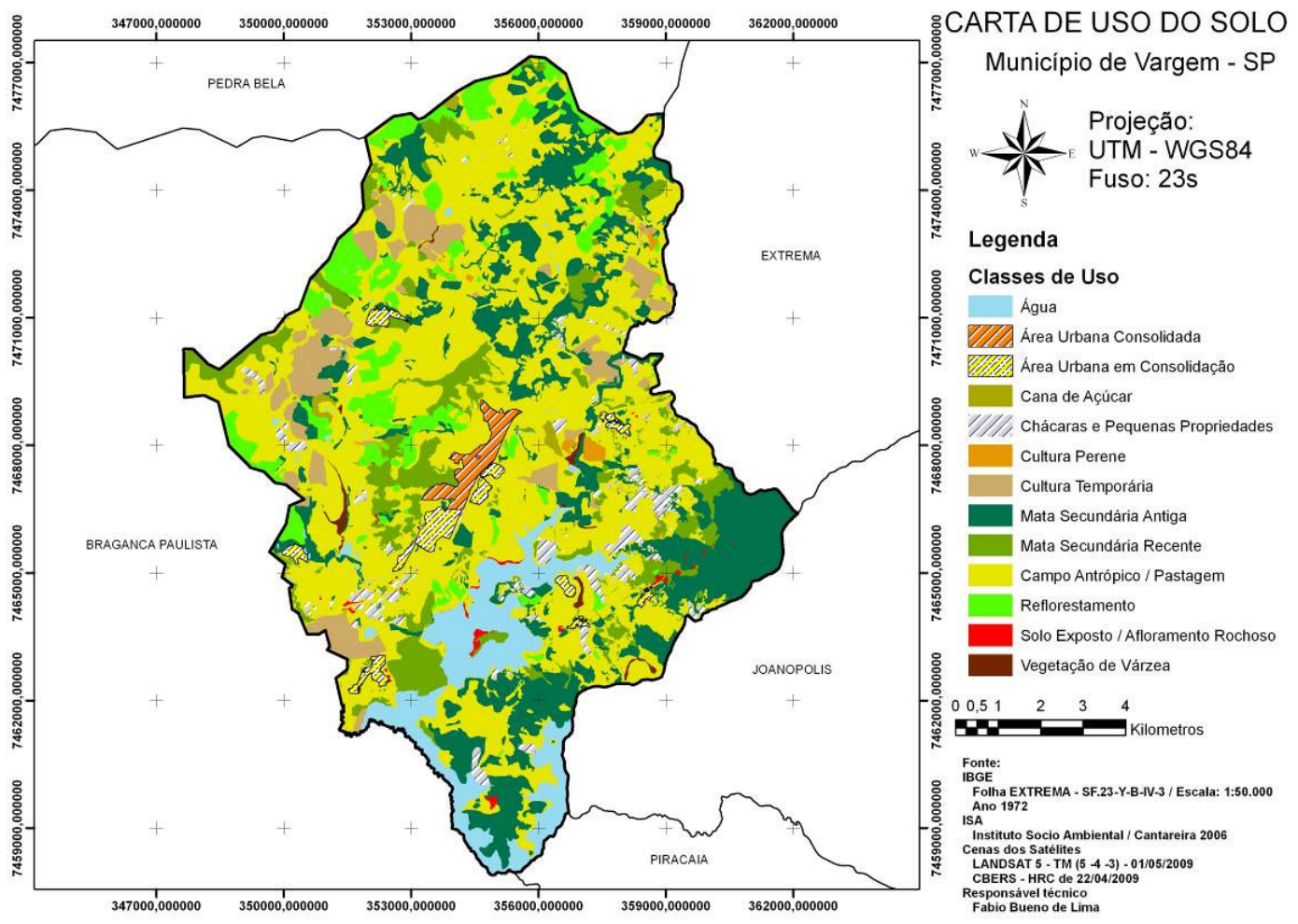

Figura 1. Carta de Uso do Solo de Vargem-SP

Os impactos ambientais decorrentes destes usos podem ser observados através do acúmulo de lixo em vários pontos da represa, dos desmatamentos, queimadas e limpezas de sub-bosque e da grande aglomeração de pessoas em diversas áreas naturais e urbanizadas, que não apresentam infra-estrutura adequada, planejamento 
turístico e práticas de Educação Ambiental.

Entretanto, a resolução dos conflitos ambientais e de uso dos recursos naturais presentes no município exige a formulação de políticas públicas que subsidiem propostas de planejamento, entre elas, as de turismo sustentável e as de Educação Ambiental, e que envolvam parcerias, tanto na sua elaboração quanto na sua implantação, entre os diferentes atores sociais locais, tais como, membros da comunidade, representantes do poder público, técnicos de órgãos públicos e privados e instituições de ensino e pesquisa.

Neste sentido vem se desenvolvendo o projeto de pesquisa Parcerias Ambientais - Diagnóstico Turístico e Propostas de Educação Ambiental em Vargem-SP, processo 2006/51790-8, integrante do programa de Políticas Públicas da FAPESP, visando contribuir para a implementação de políticas municipais voltadas ao turismo sustentável e participativo em Vargem.

Dentre as metodologias adotadas, destaca-se a adaptada do trabalho de Irving (2006), para construção do plano de trabalho, que envolve quatro fases:

\section{Fase Exploratória:}

Fase em que os pesquisadores de forma integrada definiram o tema, o plano de trabalho, os objetivos e as metodologias, preocupando-se em realizar coletivamente as reflexões e ações.

\section{Fase de Desenvolvimento:}

Nesta fase os pesquisadores estão desenvolvendo o inventário, as pesquisas de oferta e demanda turística, a confecção de mapas temáticos e as propostas de Educação Ambiental visando a elaboração do diagnóstico turístico-ambiental a partir de trabalhos de campo e bibliográficos e as analises e interpretações dos dados. Conforme as etapas da pesquisa vão consolidando-se estão sendo apresentadas de forma conjunta para os diferentes atores sociais participantes do projeto. A discussão e a interpretação de dados estão sendo realizadas juntamente com o grupo de trabalho, formado pelos proponentes do projeto e pesquisadores do Centro de Estudos Ambientais Sociedades e Naturezas da Universidade São Francisco, os parceiros representados por membros da Prefeitura Municipal de Vargem e da Coordenadoria de Assistência Técnica Integral (CATI) e os colaboradores da Companhia de Saneamento Básico do Estado de São Paulo (SABESP), Zagaia Consultoria, Planejamento e Pesquisa em Turismo e Associação Entre Amigos (FIGURA 2). 


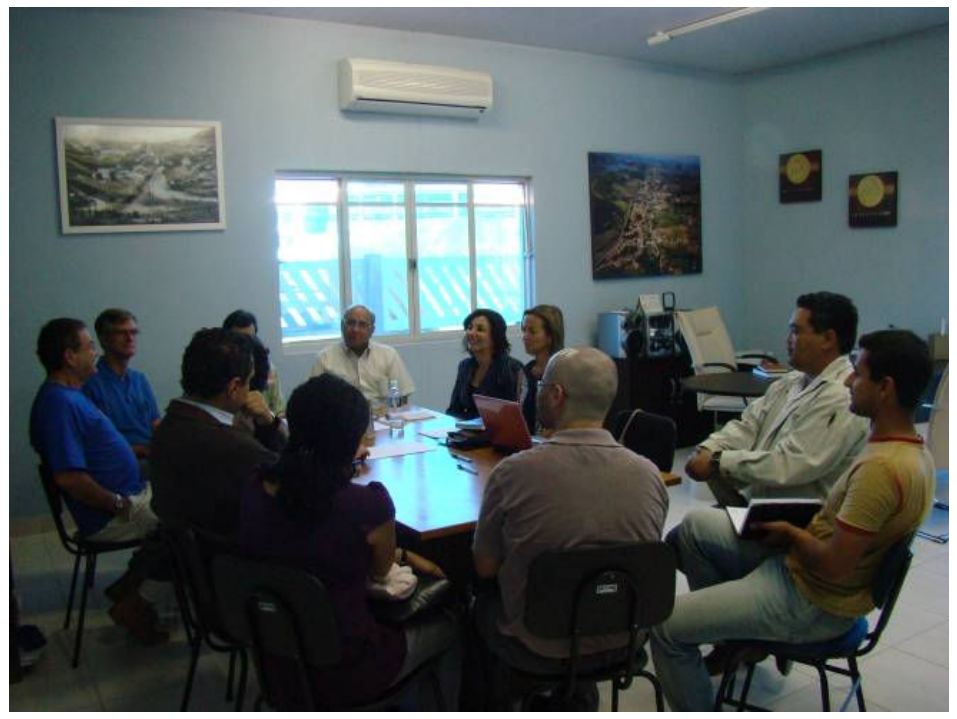

Figura 2: Reunião de Trabalho juntamente com os parceiros e colaboradores

Destaca-se nesta fase a realização de duas audiências públicas, cujos convites foram distribuídos em lugares estratégicos do município, como supermercados, feiras, saídas das missas, entre outros (FIGURA 3), onde foi possível apresentar a proposta do trabalho e os resultados obtidos até o presente momento para os diferentes atores sociais do município de Vargem. Relevante também foi a possibilidade, nestes encontros, de obter a contribuição dos presentes com informações complementares e também identificar das aspirações destes para com a localidade.

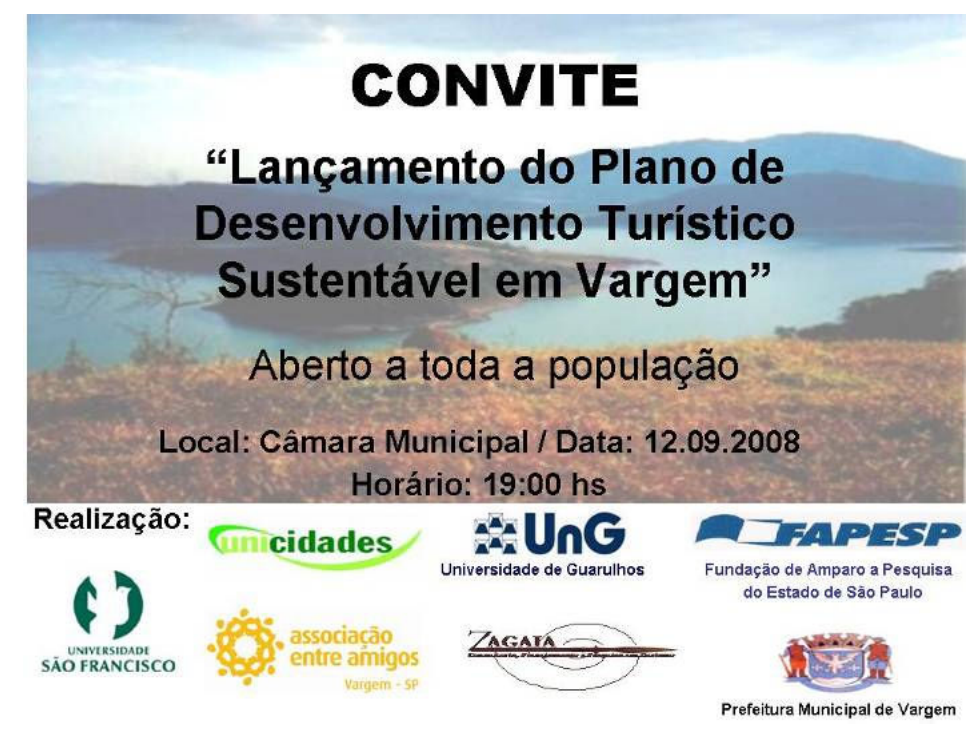

Figura 3. Convite de lançamento para $1^{\circ}$ Audiência Publica em Vargem 
As próximas audiências ocorrerão para apresentação dos dados das pesquisas de oferta e demanda e também do diagnóstico turístico-ambiental. Estes encontros vêm possibilitando à equipe de trabalho lidar com determinados conflitos decorrentes de percepções divergentes e choques de personalidades, porém acredita-se que este processo está sendo enriquecedor para todos os atores e em especial para o fortalecimento do espírito participativo em formulação de políticas públicas (FIGURAS 4 e 5).
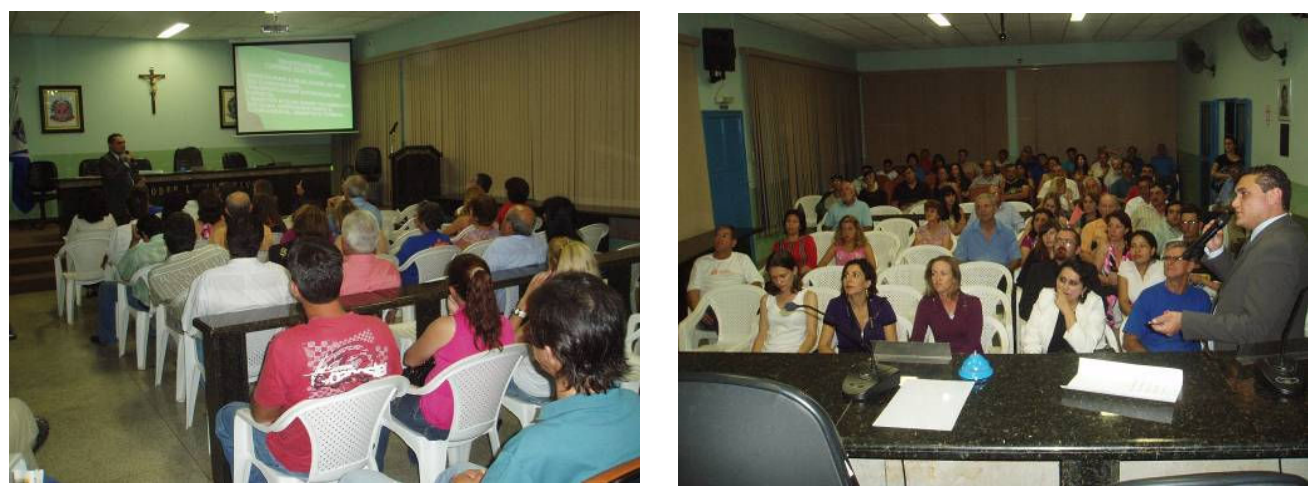

Figuras 4 e 5: Participação popular durante as audiências públicas

Estas audiências estão sendo um marco do projeto, já que vem sendo possível enfatizar a pesquisa como um instrumento de análise e de potencialidades turísticas existentes no município, mas que deve ser implementado e transformado em políticas públicas, cabendo aos atores sociais, a partir de sua participação e tomadas de decisão, a exigência da incorporação destas propostas pelo poder municipal. Este processo de audiências integra uma das propostas de Educação Ambiental que busca o fortalecimento da sociedade civil a partir de propostas participativas.

\section{Fase de Ação (construção):}

Com base nas fases anteriores e na concretização dos objetivos, será entregue à gestão pública municipal os resultados da pesquisa, buscando assim subsidiar a implementação de um Plano de Ação visando um turismo sustentável.

\section{Fase de Avaliação e Acompanhamento:}

Durante todo o processo observa-se e debate-se sobre os rumos da pesquisa, visando redirecionar e/ou ajustar as metas e as prioridades. Esta etapa vem envolvendo a análise conjunta do trabalho e a projeção de cenários de curto, médio e longo prazo e iniciou-se imediatamente após o planejamento das ações e a sistematização dos resultados alcançados, por meio da participação de todos os envolvidos. 
Estas etapas metodológicas vêm ocorrendo desde 2006, quando foi aprovada pela FAPESP a Primeira Fase do Projeto de Auxílio à Pesquisa - Políticas Públicas (seis meses) e a partir de 2008 iniciou-se a Segunda Fase com um período de dois anos, sendo que o mesmo terá o seu termino em Maio de 2010. Destacase que a primeira fase ocorreu junto a uma gestão administrativa municipal e a segunda fase, devido ao processo eleitoral, com outra administração pública, porém deve-se mencionar que este fato não alterou, até o presente momento, significativamente $o$ andamento do mesmo.

\section{Algumas Considerações}

Nas últimas décadas a participação social tem sido a tônica em questões que envolvem diversos temas, em especial, assuntos controversos apresentados por órgãos governamentais que necessitam de tomadas de decisões conjuntas para tornarem-se válidas frente à opinião pública. No entanto, na maioria das vezes, a temática a ser votada não foi devidamente debatida, deixando para a população uma incumbência para a qual a mesma não se encontra totalmente preparada, já que necessitaria de um entendimento mais amplo sobre as complexidades das propostas.

Neste sentido, tornam-se válidas as pesquisas voltadas para a criação de estratégias de fortalecimento das opiniões e decisões populares, que envolvam mecanismos que promovam o encontro e estimulem a participação. $O$ projeto de políticas públicas aqui apresentado - um diagnóstico turístico-ambiental para o município de Vargem - busca envolver a população no processo de pesquisa, já que o compromisso da implementação deste estudo cabe ao órgão governamental, necessitando desta forma do apoio e da pressão popular para que o mesmo se efetive.

Vargem que teve a sua emancipação decorrente de processos reivindicatórios, embora com diversos e diferentes interesses, torna-se um município interessante para se buscar um fortalecimento de participação a partir de sua própria história, podendo até mesmo destacar-se como uma localidade que valoriza os princípios democráticos de decisão. Acredita-se que a construção de um processo participativo que busque junto com a população identificar potenciais e possibilidades de atividades econômicas possa viabilizar um processo de desenvolvimento local sustentável, incluindo as atividades turísticas. 


\section{Referências Bibliográficas}

BRUSEKE, F. J. O problema do Desenvolvimento Sustentável. In: CAVALCANTI, C. (org.). Desenvolvimento e Natureza: Estudos para uma sociedade sustentável. São Paulo: Cortez; Recife: Fundação Joaquim Nabuco, 1998, p. 29-40.

CABRAL, N.R.A.J.; SOUZA, M.P. Área de Proteção Ambiental: Planejamento e Gestão de Paisagens Protegidas. São Carlos: Rima, 2002.

CMMAD. Nosso Futuro Comum. $2^{\circ}$ ed. Rio de Janeiro: Fundação Getúlio Vargas, 1991.

CRUZ, R. C. Política de turismo e território. São Paulo: Contexto, 2000.

DIAS, R. Turismo Sustentável e Meio Ambiente. São Paulo: Atlas, 2003.

DIEGUES, A. C.; NOGARA, P. J. O nosso lugar virou parque - Estudo sócioambiental do Saco de Mamanguá - Parati - Rio de Janeiro. São Paulo: NUPAUB-USP, 1999.

DOWBOR, L. O que é poder local? São Paulo: Brasiliense, 1999. Col. Primeiros Passos, n. 285.

FADINI, A.A.B. Sustentabilidade e Identidade Local: Pauta para um Planejamento Ambiental Participativo em Sub-Bacias Hidrográficas da Região Bragantina. Rio Claro: Tese de Doutorado em Geografia - Organização do Espaço. Instituto de Geociências e Ciências Exatas, Universidade Estadual Paulista, 2005.

FOLADORI, G. Limites do desenvolvimento sustentável. Campinas: Ed. da Unicamp, 2001, 221p.

FREIRE, P. Pedagogia do Oprimido. Rio de Janeiro: Paz e Terra, 1975.

FURTADO, C. O mito do desenvolvimento econômico. Rio de Janeiro: Paz e Terra, 1974.

IRVING, M.A.; Áreas de Protegidas e Inclusão Social: Construindo novos significados. Rio de Janeiro: Fundação Bio-Rio: Núcleo de Produção Editorial Aquarius, 2006. 
LOUREIRO, C.F.B.; AZAZIEL, M.; FRANCA, N. (Orgs.). Educação Ambiental e gestão participativa em Unidades de Conservação. Rio de Janeiro: IBASE/IBAMA, 2003.

MARICATO, E. As idéias fora do lugar e o lugar fora das idéias - Planejamento Urbano no Brasil. In: ARANTES, O.; VAINER, C.; MARICATO, E. (Orgs). A cidade do pensamento único: Desmanchando Consensos. Petrópolis: Vozes, 2000, p. $121-92$.

MOLINARI, J. B. VARGEM: Origem e Formação Questão de Divisas São Paulo - Minas Gerais. Gráfica Leal, 2004.

MOREIRA ALVES, M. A força do povo: Democracia participativa em Lages. São Paulo: Brasiliense, 1980, $150 \mathrm{p}$.

MORIN, E. Os sete saberes necessários à educação do futuro. São Paulo: Cortez; Brasília, DF, UNESCO, 2002, 118 p.

NOVAES, W. A década do impasse: Da Rio 92 à Rio + 10. São Paulo: Estação Liberdade: Instituto Socioambiental, 2002, p. 381.

PIMBERT, M. P. \& PRETTY, J. N.; Parques, Comunidades e Profissionais: Incluindo "Participação" no Manejo de Áreas Protegidas. In: DIEGUES, A.C. (Org.). Etnoconservação: Novos rumos para a proteção da natureza nos trópicos. São Paulo: Annablume; NUPAUB-USP; Hucitec, 2000, p. 183-223.

SACHS, I. Caminhos para o desenvolvimento sustentável. Rio de Janeiro: Garamond, 2000, 95p.

SANTOS, A. D. dos. Metodologias Participativas: Caminhos para o fortalecimento de espaços públicos socioambientais. São Paulo: Petrópolis, 2005.

SÃO PAULO. Secretaria de Estado do Meio Ambiente. Atlas das Unidades de Conservação Ambiental do Estado de São Paulo. São Paulo: SMA, 2000.

SUAREZ, C. F. e S. Turismo e Sustentabilidade: A demanda turística e seus principais impactos sócio-ambientais em Monte Verde - Camanducaia - MG. Dissertação de Mestrado. São Paulo: UNIBERO, 2003. 
Almerinda Antonia Barbosa Fadini: Universidade São Francisco. Email: almerindafadini@hotmail.com

Link para o currículo Lattes: http://lattes.cnpq.br/7835878522109146

Evandro da Silva Fermino: Universidade São Francisco (bolsista).

Email: eubio4@gmail.com

Link para o currículo Lattes: http://lattes.cnpq.br/9969411236981563

João Luiz de Moraes Hoefel: Universidade São Francisco.

Email: jlhoeffel@hotmail.com

Link para o currículo Lattes: http://lattes.cnpq.br/7635072427530391

Cristiane Ferráz e Silva Suarez: Doutoranda em Ambiente e Sociedade pelo NEPAM/UNICAMP; e Universidade São Francisco.

Email: cristiane.suarez@saofrancisco.edu.br

Link para o currículo Lattes: http://lattes.cnpq.br/7955383731847589

Data de submissão: 29 de outubro de 2009.

Data do aceite: 12 de dezembro de 2009 . 